\title{
Recurrent Invasive Ductal Breast Carcinoma
}

National Cancer Institute

\section{Source}

National Cancer Institute. Recurrent Invasive Ductal Breast Carcinoma. NCI Thesaurus.

Code C153587.

The reemergence of invasive ductal breast carcinoma after a period of remission. 